\title{
A PRIMEIRA REPÚBLICA PORTUGUESA RECRIA O MINISTÉRIO DA INSTRUÇÃO PÚBLICA: UM ESFORÇO DE APROXIMAÇÃO AOS SISTEMAS ESCOLARES EUROPEUS ${ }^{1}$
}

\author{
DOI: http://dx.doi.org/10.1590/2236-3459/63180
}

\author{
Carlos Manique da Silva \\ Instituto de Educação, Universidade de Lisboa, Portugal.
}

$\cos 80$

\begin{abstract}
Resumo
No presente artigo procuro perceber em que medida a existência de um Ministério próprio, no fundo, de uma estrutura administrativa fortemente centralizada para a gestão da escola, contribuiu nos anos subsequentes a 1913, data de reinstituição definitiva do Ministério da Instrução Pública, e até sensivelmente ao final da Primeira República portuguesa (1926), para a aproximação aos sistemas escolares europeus. Num primeiro momento analiso os projetos-leis discutidos na Câmara de Deputados e no Senado a respeito da mencionada reinstituição. Posteriormente identifico algumas estratégias e medidas adotadas na esfera do Ministério da Instrução Pública, designadamente as que visavam a renovar o sistema educativo português no sentido de o tornar comparável ao de alguns países europeus. Concluo que, nesse período histórico, marcado por grande instabilidade política, a existência de um órgão central de coordenação do sistema educativo não se traduziu em maior capacidade para desenvolver de forma coerente dinâmicas inovadoras.

Palavras-chave: Ministério da Instrução Pública, Portugal, Primeira República Portuguesa, viagens pedagógicas.
\end{abstract}

\section{THE PORTUGUESE FIRST REPUBLIC BRINGS BACK THE MINISTRY OF PUBLIC INSTRUCTION: AN APROACHING EFFORT TO THE EUROPEAN SCHOOL SYSTEMS}

\begin{abstract}
The aim of this article is to understand how, the existence of a separate ministry, that is, a highly centralized administrative structure for the school management, contributed in the years after 1913, date of final reinstitution of the Ministry of Public Instruction, nearly to the end of the First Portuguese Republic (1926), for the approach to European school systems. At first, I analyse the project-laws discussed in the Chamber of Deputies and the Senate of the above mentioned reinstatement. Later, I analyse some strategies or measures adopted in the sphere of the Ministry of Public Instruction, those that aimed reviving the Portuguese education system in order to make it
\end{abstract}

\footnotetext{
${ }^{1}$ Agradeço à professora Áurea Adão pelas sugestões e impressões trocadas sobre o tema.
} \begin{tabular}{|l|l|l|l|l} 
Hist. Educ. (Online) & Porto Alegre & v. 20 & n. 50 & Set./dez., 2016
\end{tabular} 
similar to some European countries. I conclude that, in this historical period marked by great political instability, the existence of a central structure to coordinate the education system has not translated into greater capacity to develop consistently innovative dynamics.

Key-words: Ministry of Public Education, Portugal, First Portuguese Republic, pedagogical trips.

\title{
LA PRIMERA REPÚBLICA PORTUGUESA RECREA EL MINISTERIO DE INSTRUCCIÓN PÚBLICA: UN ESFUERZO DE APROXIMACIÓN A LOS SISTEMAS ESCOLARES EUROPEOS
}

\begin{abstract}
Resumen
En este artículo intento comprender en qué medida la existencia de un ministerio propio, en realidad, de una estructura administrativa fuertemente centralizada para la gestión de la escuela, contribuyó en los años siguientes a 1913, fecha de la reinstitución definitiva del Ministerio de Instrucción Pública, y casi hasta el final de la Primera República Portuguesa (1926), a la aproximación a los sistemas escolares europeos. En un primer momento, analizo los proyectos de ley sobre la mencionada re institución, discutidos en el Congreso de los Diputados y en el Senado. Posteriormente identifico algunas estrategias o medidas adoptadas por el Ministerio de Instrucción Pública, especialmente las que pretenden renovar el sistema educativo portugués para que pueda ser comparable al sistema de algunos países europeos. Concluyo que, en ese periodo de la historia, caracterizado por una gran inestabilidad política, la existencia de un órgano central de coordinación del sistema educativo no se tradujo en una mayor capacidad para desarrollar de manera coherente dinámicas innovadoras.

Palabras-clave: Ministerio de Instrucción Pública, Portugal, Primera República Portuguesa, viajes pedagógicos.
\end{abstract}

\section{LA PREMIERE REPUBLIQUE PORTUGAISE RECREEE LE MINISTERE DE L'INSTRUCTION PUBLIQUE : UN EFFORT D'APPROXIMATION AUX SYSTEMES SCOLAIRES EUROPEENNES}

\section{Résumé}

Dans cet article, je cherche à comprendre dans quelle mesure l'existence d'un ministère distinct, ça veut dire, une structure administrative très centralisée pour la gestion de l'école a contribué dans les années après 1913, la date finale du rétablissement du Ministère de l'Instruction Publique, et tout près de la fin de la Première République portugaise (1926), pour l'approche aux systèmes scolaires européens. Dans un premier moment, j'analyse les projets-lois discutées dans la Chambre des Députés et dans le Sénat, concernant la réintégration mentionné ci-dessus. Après, j'analyse des stratégies et mesures adoptées dans le domaine du Ministère de l'Instruction Publique, particulièrement celles visant à relancer le système éducatif portugais afin de le rendre comparable à certains pays européens. Je conclus que, dans cette période historique marquée par une grande instabilité politique, l'existence d'un organisme central de coordination du système éducatif ne s'est pas traduite dans une plus grande capacité à développer des dynamiques innovatrices, d'une façon consistent.

Mots-clé: Ministère de l'Instruction Publique, Portugal, Première République portugaise, voyages pédagogiques. 


\section{Introdução}

A reinstituição do Ministério da Instrução Pública ocorreu em 7 de julho de $1913^{2}$, durante o governo de Afonso Costa, consagrando uma velha aposta do republicanismo português. Trata-se, porém, de uma medida que começou a ganhar corpo no início do ano de 1912, no âmbito da reorganização do Ministério do Interior. De facto, este Ministério, antes da instauração da República, em 5 de outubro de 1910, de denominação genérica do Reino, tinha um campo de atuação muito abrangente, tutelando funções nos domínios da administração política e civil, da segurança pública, da saúde, da assistência, da educação. Ora, em fevereiro de 1912, Silvestre Falcão, ministro do Interior, confrontado no Senado com o atraso dos pagamentos das rendas dos imóveis onde se encontravam instaladas as escolas primárias, reconheceu que esse problema decorria da sobrecarga de serviço por que passava o seu Ministério. Todavia, manifestou nesse mesmo momento a seguinte esperança:

quando se fizer o desdobramento do Ministério do Interior, se possa remodelar muito o serviço. Esse desdobramento, que parece simples, é também complicado [...] Há uma dificuldade enorme em destrinçar, separar o que deve ficar em cada um dos Ministérios. (Diário do Senado, sessão de 26 fev. 1912, p. 6)

No decurso do primeiro trimestre de 1912 o próprio ministro Silvestre Falcão apresentou à Câmara dos Deputados um projeto-lei visando à criação do Ministério de Instrução e Arte (Diário da Câmara dos Deputados, sessão de 13 mar., 1912). Nesse preciso trimestre Pádua Correia, deputado, assinou de igual modo um projeto-lei com idêntico fim (Diário da Câmara dos Deputados, sessão de 18 mar., 1912). Sucederia, ainda, que a Comissão de Instrução Pública da Câmara dos Deputados, analisando os mencionados projetos-leis e, na prática, modificando-os, elaboraria um conjunto de bases, em rigor um novo projeto-lei, tendo em vista o mesmo propósito (Diário da Câmara dos Deputados, sessão de 13 nov., 1912). Entre o final do ano de 1912 e julho de 1913 os debates que ocorreram, tanto na Câmara dos Deputados, quanto no Senado, denunciam a dificuldade em concertar posições em torno da estrutura administrativa e das funções do novo Ministério.

Ao longo do presente texto é minha intenção perceber em que medida a existência de um Ministério próprio, no fundo, de uma estrutura administrativa fortemente centralizada para a gestão da escola, contribuiu nos anos subsequentes a 1913 e até sensivelmente ao final da Primeira República (1926), para a aproximação aos sistemas escolares europeus. De resto, há uma ideia que importa ter presente: a de que "nationstates take up the world models of educational ministries and laws because they believe the education systems would enhance their economic development and social progress" (Kim, 2006, p. 149).

2 O Ministério teve existência efémera no decurso da segunda metade do século 19: Ministério dos Negócios da Instrução Pública (1870); Ministério da Instrução Pública e Belas-Artes (1890-1892). A instituição republicana do Ministério será definitiva, não obstante as várias designações que foi tendo ao longo de mais de um século.

Hist. Educ. (Online) $\quad$ Porto Alegre

v. 20

ก. 50

Set./dez., 2016

p. $373-387$ 
Os debates na Câmara dos Deputados e no Senado em torno dos diplomas de reinstituição do Ministério (1912-1913)

Comecemos por conhecer as considerações expressas por Silvestre Falcão e Pádua Correia nos preâmbulos dos respetivos projetos-leis, tendo por referência, justamente, a sessão parlamentar de 13 de novembro de 1912, na qual começam a ser discutidos. Para o ex-ministro do Interior $^{3}$ os assuntos educativos exigiam particular especialização, pressupondo mesmo uma forte cultura filosófica e social, não sendo, no seu entender, compagináveis com as caraterísticas do Ministério do Interior, cujas áreas de governação, na essência, tinham que ver com a política e administração interna, algo que tornava inevitável a marginalização do campo educativo.

Por outro lado, adiantava ainda Silvestre Falcão, o facto de existirem à data duas direções-gerais responsáveis pela área da educação, na prática sem coordenação superior, conduzia a que as reformas se sucedessem "desconcertadas e fragmentárias fazendo e desfazendo, sem espírito de sequência" (Diário da Câmara dos Deputados, sessão de 13 nov., 1912, p. 8). Considera então haver duas possibilidades para solucionar o problema, a saber: ou a criação de uma direção-geral única, o que seria de alguma maneira o regresso ao modelo da Direção-Geral de Instrução Pública, ou autonomizar do Ministério do Interior a área da educação e criar assim uma pasta própria, que tutelaria também estabelecimentos de ensino dependentes do Ministério do Fomento. Do seu ponto de vista, no entanto, a primeira solução seria um claro retrocesso.

Por seu turno, as motivações subjacentes ao projeto-lei assinado por Pádua Correia não divergiam, no essencial, das do diploma da autoria do ministro Silvestre Falcão. Todavia, o citado deputado enraizava historicamente a existência de um Ministério próprio na ação do primeiro responsável pela pasta da Instrução Pública em Portugal, D. António da Costa. Volvidas quatro décadas, Pádua Correia considerava que o argumento que levara D. António a criar o Ministério dos Negócios da Instrução Pública (1870) permanecia pleno de atualidade, ou seja, a interferência da política nos assuntos da educação. No momento presente, porém, segundo acrescentava, havia além do mais a necessidade de uma estrutura administrativa capaz de coordenar o ensino técnico e profissional, a cargo do Ministério do Fomento, e o ensino colonial, tutelado pelo Ministério das Colónias, com o ensino científico e literário que estava sob a dependência do Ministério do Interior. Por outro lado, Pádua Correia sustentava, na nota preambular, que o pessoal superior do Ministério da Instrução Pública deveria ser recrutado "com o maior cuidado entre os especialistas e profissionais do ensino" (Diário da Câmara dos Deputados, sessão de 13 nov. 1912, p. 10). Conviria, de resto, que o ministro fosse um professor do ensino oficial.

No respeitante à estrutura administrativa do novo Ministério, apenas o projeto que era assinado por Pádua Correia consagrava a existência de uma secretaria-geral, que coordenaria as direções-gerais. Ambos, porém, previam a existência de três direçõesgerais, tutelando os serviços dos seguintes níveis de ensino: primário; secundário e superior; técnico e profissional. A estrutura do ministério proposta por Pádua Correia significativamente mais complexa daquela que fora pensada por Silvestre Falcão mantinha também o Conselho Superior de Instrução Pública, bem como diversas

\footnotetext{
${ }^{3}$ À data da discussão que estamos a acompanhar, Silvestre Falcão já não exercia as funções de ministro do Interior. 
comissões de trabalhos científicos ligadas a estudos de natureza antropológica, etnológica e filológica, estudos cujos objetivos passavam pela identificação do tipo e dos costumes do povo português, pela elaboração de uma história da literatura, pela organização do folclore nacional, entre outros. Encontramos aqui o pressuposto de que o Ministério da Instrução Pública desempenharia um papel importante na consolidação dos signos da identidade da nação. Interessa ainda referir que, no texto apresentado por Pádua Correia, não ficavam esquecidas as publicações periódicas, a exemplo de um boletim ou revista destinado a divulgar artigos sobre pedagogia, pedologia, legislação escolar estrangeira e bibliografia.

O debate parlamentar em torno dos mencionados projetos integrou também o já citado parecer da Comissão de Instrução Pública, assim como outro parecer emitido pela Comissão de Finanças. Este último era decididamente a favor do projeto-lei da autoria de Silvestre Falcão, por ser o mais económico e o "mais sintético" (Diário da Câmara dos Deputados, sessão de 13 nov. 1912, p. 8). Por outro lado, o parecer redigido pela comissão conjunta de instrução pública, baseado nos dois projetos-leis, seguia em grande medida o projeto de Pádua Correia, prevendo, designadamente, a mesma estrutura administrativa para o novo Ministério.

Impõe-se referir que a discussão não seguiu uma via linear, uma vez que foram sendo dirigidas várias críticas aos funcionários do Ministério do Interior. Em função disso, chega mesmo a veicular-se a ideia de que com a República "os negócios da instrução" haviam piorado (Diário da Câmara dos Deputados, sessão de 13 nov. 1912, p. 17). Mas, recentrando o debate nas bases apresentadas pela comissão de instrução pública, tratava-se, em bom rigor, de um novo projeto-lei, Duarte Leite, ministro do Interior, vê na recriação do Ministério da Instrução Pública e Belas-Artes a oportunidade de fazer uma reforma de ensino "harmonicamente num plano geral, com unidade" (p. 18). Descrê, porém, ao contrário da generalidade dos atores, de que com um ministério próprio desapareça a pressão política.

A discussão do dito projeto-lei prossegue na especialidade no dia 14 de novembro do referido ano. Acontece, porém, que todo o labor em torno desse diploma viria a revelarse infrutífero. Efetivamente, na sessão do Senado de 27 de janeiro de 1913, a comissão de instrução pública, desta feita do Senado, apresentou um novo projeto-lei, argumentando não concordar inteiramente com aquele que havia sido devolvido pela Câmara dos Deputados. É patente que o citado projeto - no seu articulado muito próximo do diploma final - integra alguns contributos do parecer emitido, em 1912, pela Sociedade de Estudos Pedagógicos. É exemplo a designação adotada para o Ministério - da Educação -, termo que, segundo a mesma Sociedade, estaria "mais de acordo com as ideias modernas que, decididamente, subordinam a instrução à educação" (Diário das Sessões do Senado, sessão de 19 nov. 1912, p. 11). Em linha está também a vontade de incluir no Ministério da Educação todos os estabelecimentos de ensino públicos, excetuando os que eram tutelados pelos Ministérios da Guerra e da Marinha, assim como o Conselho Superior de Instrução Pública.

No entanto, o projeto-lei da responsabilidade da Comissão de Instrução Pública do Senado introduzia uma novidade absoluta no respeitante à organização do Ministério, ou seja, a inexistência de qualquer direção-geral. De facto, no desenho organizacional estavam previstas uma secretaria-geral e sete repartições. A intenção, segundo se 
expressava, era a de "diminuir o estado maior burocrático que pesa[va] tão duramente sobre o orçamento" (Diário das Sessões do Senado, sessão de 27 jan. 1913, p. 14). Porém, do meu ponto de vista, estamos perante uma solução de compromisso, uma vez que as sete repartições, igualmente autónomas, tinham como missão tutelar os serviços dos diferentes níveis de ensino - primário e normal, secundário, superior -, bem como os dos ensinos artístico, agrícola e técnico. Os chefes de repartição, obrigatoriamente professores das especialidades, ficavam na dependência direta do ministro. Procurava-se, desse modo, vencer alguns antagonismos e, mesmo, pressões em torno da importância de determinados setores de ensino, conferindo-lhes idêntico estatuto.

Nas discussões ocorridas no Senado, em fevereiro de 1913, são relevantes as sessões dos dias 6 e 7, consagra-se, em boa medida, conforme se anunciou, a proposta da Comissão de Instrução Pública do Senado.

\section{Esforços para elevar o ensino público àquela altura que em todos os países cultos tem atingido: a intervenção do Ministério da Instrução Pública}

É certo, conforme indicam Gondra e Mignot (2007), que o "processo de afirmação da escola moderna supõe observar o seu aparecimento e legitimação para além das fronteiras nacionais" (p. 7). No caso português, por exemplo, durante as três primeiras décadas do século 20, uma das estratégias adotadas para promover o contato com modelos educativos estrangeiros foram as viagens pedagógicas a países europeus de referência no campo educativo. O objetivo, que não constituía novidade, era o de que os educadores bolseiros, contatando com inovações produzidas nesses países, "contribuíssem depois para a sua difusão em Portugal e, consequentemente, para a modernização do sistema de ensino" (Pintassilgo, 2007, p. 195). A missão desses bolseiros está, em parte, estudada, sobretudo no quadro das viagens realizadas no final da monarquia, 1907-1909 (Fernandes, 1971, 1995; Pintassilgo, 2007; Silva, 2013), assim como nas décadas de 1910 a 1930 (Hameline; Nóvoa, 1990; Fernandes, 2007).

Deve, no entanto, revelar-se que o Ministério do Interior aprovou, entre o segundo semestre de 1911 e o mesmo semestre do ano seguinte, um conjunto de cerca de trinta bolsas de estudo no estrangeiro, sobretudo na área da Medicina. De facto, entre os bolseiros ou pensionistas contavam-se figuras como as dos médicos Reinaldo dos Santos, José de Matos Sobral Cid e António Aurélio da Costa Ferreira, para só citar algumas, bem como provenientes de outras áreas do saber, a exemplo de Virgínia Guerra Quaresma, encarregue de estudar os estabelecimentos modelares femininos na França, Alemanha Suíça e Itália (IAN/TT, Ministério do Interior, Secretaria-Geral, maço 567, cx. 78, Iv. 1, n. 235).

Ora, a partir de 1913, depois de criado o novo ministério, encontramos idênticas preocupações. A este respeito, creio ser relevante o mandato do ministro José de Matos Sobral Cid, exercido entre fevereiro e dezembro do ano de 1914, por sinal um dos mais longos na Primeira República. De resto é muito interessante que Alice Pestana considere serem significativas, dentro da exiguidade dos recursos do país, as verbas destinadas ao ensino público (Pestana, 1915). O exemplo que dá é, muito justamente, o do orçamento para o ano económico de 1914-1915, assinado por Sobral Cid (Pestana, 1915). Não obstante criticar, em anterior passagem da referida obra, a excessiva centralização, Alice Pestana julga de forma positiva a existência de um órgão central de coordenação de todo 
o sistema educativo. Chega mesmo a comparar, no referente à instrução pública, o último orçamento da monarquia com o de 1914-1915. Porém, não tirando conclusões definitivas, deixa presente a ideia de a administração do novo Ministério ser mais criteriosa na maneira de aplicar os fundos (Pestana, 1915).

Mas, voltando ao mandato do ministro Sobral Cid, o relatório do Ministério da Instrução, publicado nas Obras (Cid, 1983), dá bem a medida da sua intervenção no que aos vários níveis de ensino concerne. Sublinha-se o papel que desempenhou no fomento do ensino experimental da Física, Química, Biologia, Geologia e Geografia. Para esse caminho contribuiu certamente, na linha, aliás, do que foi sustentado por Aires Diniz e Jorge Bonito (2010), o conhecimento que Sobral Cid tinha das realidades extrafronteiras, o qual decorria, em boa parte, das missões científicas realizadas nos anos de 1908 e de 1913. Há dois aspetos que estão bem presentes no seu pensamento. Por um lado, a reformulação dos métodos pedagógicos, por outro lado, o desenvolvimento da investigação científica. Se considerarmos o ensino secundário, onde o ministro teve uma ação significativa, à semelhança do que sucedeu em outros níveis de ensino, vale referir a introdução nos liceus da prática dos trabalhos individuais educativos, nas disciplinas de Física, Química, História Natural e Geografia:

Às demonstrações práticas a que os professores são obrigados durante o curso associámos assim o trabalho ativo e individual dos discípulos, sob a sua direção. A estes trabalhos demos o caráter de investigação livre de que interessem o aluno, fugindo da execução maquinal de receituários de experiências consabidas em cuja génese e organização o seu espírito não toma uma parte ativa. (Cid, 1983, p. 370)

Para esse fim, era, obviamente, indispensável material didático, tendo sido adquiridas "importantes coleções para o liceu Passos Manuel" (Cid, 1983, p. 368), sendo que os restantes estabelecimentos liceais foram, de igual modo, beneficiados. Não bastava, porém, perfilhar os citados pressupostos e ter a referida ação sem considerar a preparação pedagógica e científica dos docentes. Na verdade, ao abrigo de nova regulamentação, passavam a ser requeridos conhecimentos e habilitações nas ciências histórico-naturais, tendo as provas ao magistério um caráter não apenas teórico, mas também prático, pressupondo, assim, a utilização dos métodos de investigação científica (Cid, 1983).

Não é este o espaço próprio para aprofundar a intervenção de Sobral Cid à frente dos destinos do Ministério da Instrução Pública. Antes, porém, de abordar o exercício de outro ministro, julgo útil enfatizar o esforço realizado ao longo do ano de 1914 no sentido de aproximar o sistema educativo português dos congéneres da Europa. Destaco, a título de exemplo e muito telegraficamente, os contributos de Sobral Cid no concernente aos seguintes aspetos: à promoção do ensino industrial e comercial; à definição da autonomia universitária; à conclusão do edifício do Instituto Superior de Agronomia ${ }^{4}$, que o ministro considerava poder vir a ser "um dos melhores institutos agronómicos da Europa" (Cid, 1983, p. 384). Faço, por fim, notar o interesse pelo ensino artístico, sendo a este respeito

\footnotetext{
${ }^{4}$ No que concerne à construção de novos edifícios escolares a administração de Sobral Cid teve um papel decisivo, consignando verbas para a construção, entre outras, da Escola Normal de Lisboa, inaugurada em 1918; da Escola Primária de Alcântara, inaugurada em 1916; do Instituto Superior Técnico, obra que seria apenas iniciada em 1927. 
elucidativa a criação do curso de cenografia e decoração teatral. Uma palavra, ainda, para dizer que, segundo documentação de arquivo (cf. Arquivo Histórico do Ministério da Educação e Ciência, Ministério da Instrução Pública, ofício assinado por José Sobral Cid, 05/07/1914), na forja terá estado a ideia de reformar e aperfeiçoar o ensino ministrado no Conservatório Nacional. Uma vez mais, na linha do que referi no início desta secção, a legitimação dessa reforma passava pelo conhecimento de experiências pedagógicas estrangeiras, designadamente italiana e francesa.

Conforme afirmou António Nóvoa o ensino secundário "foi a área onde a ação republicana se exerceu de forma menos inovadora" (Nóvoa, 1989, p. XXV), no sentido em que, até ao ano de 1918, permaneceu em vigor, apenas com ligeiras alterações, a reforma de 1895. De facto, é durante o mandato do ministro Alfredo de Magalhães, exercido entre 11 de dezembro de 1917 e 27 de janeiro de 1919, que se registam mudanças significativas. Novo enquadramento é dado pelo decreto n. 4650 , de 14 de junho de 1918, que reformava o ensino secundário. A referida legislação procedia à modificação dos planos de estudo e dos programas das disciplinas, entre outras mudanças de maior ou menor latitude. O relatório do Ministério da Instrução Pública, correspondente ao período de 11 de dezembro de 1917 a 15 de julho de 1918, assinado pelo titular da pasta, deixa clara, na fase pós-revolucionária, a relevância do ensino secundário público e particular. Na verdade, o ministro considera-o um grau

da maior importância porque abrange o mais longo currículo escolar e porque tem um objetivo de formação psicológica que o pode tornar poderosamente influente ou lamentavelmente deletério e visto tratar-se do único grau de ensino público que a República ainda não tinha reformado, à parte o episódico regulamento n. ${ }^{\circ}$ 3091, estavam previstas e em curso profundas modificações. (apud Silva, 2006, p. 128)

Na linha da investigação de António Nóvoa parece oportuno referir que, na Primeira República, a mais importante medida tomada no âmbito do ensino secundário foi a que conduziu à criação das Escolas Normais Superiores, vocacionadas "essencialmente para o professorado deste grau de ensino" (Nóvoa, 1989, p. XXVII) ${ }^{5}$. Continuou, porém, a ser prosseguida outra via no sentido da melhoria da qualidade pedagógica dos docentes, logo, deste grau de ensino: a concessão de bolsas ou pensões destinadas a suportar missões científicas no estrangeiro. É exatamente neste aspeto que pretendo agora centrar-me, mobilizando, para o efeito, documentação de arquivo produzida no âmbito das referidas viagens científicas.

O citado decreto n. 4.650, começo talvez por dizer, previa a concessão anual aos professores dos liceus de 15 subsídios destinados a "viagens de estudo aos países de mais elevada cultura intelectual, como meio de aperfeiçoamento dos métodos de ensino das disciplinas dos seus grupos". Percebe-se que a medida recebeu foros de primazia, uma vez que, antes mesmo de ser aprovado o regulamento geral da instrução secundária, decreto n. 4799, de 8 de setembro 1918, a portaria n. 1460, de 5 de agosto de 1918, vinha garantir a abertura do concurso para essas bolsas. Vejamos como essa possibilidade foi sentida por Álvaro Rodrigues Machado, professor do Liceu Rodrigues de Freitas no Porto:

\footnotetext{
${ }^{5}$ Instituídas em 1911, as Escolas Normais Superiores, que integravam as Universidades de Lisboa e de Coimbra, começaram apenas a funcionar no ano letivo de 1915/1916 (Nóvoa, 1989). 
Não quis o Ministro da Instrução, seu autor [da legislação que criava as pensões de estudo], [...] demorar-se em beneficiar a pedagogia portuguesa com os progressos realizados em países de mais elevada cultura [...] Estava então ainda ateada a grande guerra europeia, sendo impossível a viagem aos países inimigos, pouco apetecível e menos proveitosa a visita aos países neutros ou aliados do nosso, mas assolados pela guerra [...] Eu, porém, suspirava por tão salutar medida introduzida na legislação da instrução. (Arquivo Histórico do Ministério da Educação e Ciência, Ministério da Instrução Pública, Relatório do pensionista Álvaro Rodrigues Machado, 1918, documentação em fase de tratamento arquivístico)

Afigura-se útil destacar o facto de os processos de candidatura serem instruídos com rigor, obedecendo a critérios previamente definidos. Na seleção dos candidatos, por exemplo, procurava-se atender à sua competência especial, avaliada a partir de duas componentes: uma de investigação: trabalhos realizados, publicações didáticas; outra, propriamente, letiva. Interessante é também a perspetiva, consagrada na citada legislação, de haver um regime de rotação anual no respeitante aos docentes elegíveis para as bolsas, baseado no tempo de serviço. Ou seja, num ano eram unicamente opositores professores com experiência, 10 a 25 anos de serviço, sendo que no ano seguinte o concurso era apenas aberto para docentes no início de carreira, 2 a 9 anos de serviço. Há aqui, de modo óbvio, uma estratégia de melhoria a longo termo.

Figura 1 -

Candidatos a bolseiros ou pensionistas ao abrigo da portaria n. 1460, de 5 ago. 1918.

\begin{tabular}{|l|l|c|l|c|}
\hline \multicolumn{1}{|c|}{ Candidato } & Liceu de origem & Grupo & \multicolumn{1}{|c|}{ Objetivo da pensão } & $\begin{array}{c}\text { Destino } \\
\text { pretendido }\end{array}$ \\
\hline $\begin{array}{l}\text { Alberto Nunes } \\
\text { Rica* }\end{array}$ & Liceu de Camões & $1 .^{\circ}$ & $\begin{array}{l}\text { Estudar as "línguas } \\
\text { mortas", especialmente } \\
\text { latim. }\end{array}$ & Roma \\
\hline $\begin{array}{l}\text { Manuel José } \\
\text { Pereira }\end{array}$ & Liceu de Bragança & $1 .^{\circ}$ & & $\begin{array}{c}\text { Paris, Londres } \\
\text { ou Roma } \\
\text { (preferindo a } \\
\text { última cidade) }\end{array}$ \\
\hline $\begin{array}{l}\text { Adelino Eugénio } \\
\text { da Costa }\end{array}$ & Liceu de Maria Pia & $2 .^{\circ}$ & $\begin{array}{l}\text { Estudar a influência da } \\
\text { língua e literatura } \\
\text { provençal na literatura } \\
\text { portuguesa. }\end{array}$ & $\begin{array}{c}\text { Paris ou } \\
\text { Toulouse }\end{array}$ \\
\hline $\begin{array}{l}\text { António Augustorsidades) } \\
\text { Pires }\end{array}$ & Liceu de Bragança & $2 .^{\circ}$ & $\begin{array}{l}\text { Frequentar um curso de } \\
\text { férias sobre fonética e e } \\
\text { literatura francesa. }\end{array}$ & França \\
\hline $\begin{array}{l}\text { António Ferreira } \\
\text { Botelho }\end{array}$ & Liceu de Braga & $2 .^{\circ}$ & $\begin{array}{l}\text { Estudar a fonética } \\
\text { francesa. }\end{array}$ & $\begin{array}{c}\text { Grenoble } \\
\text { (Universidade) }\end{array}$ \\
\hline $\begin{array}{l}\text { António Diogo } \\
\text { do } \\
\text { Coelho Prado }\end{array}$ & Liceu de Pedro & $2 .^{\circ}$ & $\begin{array}{l}\text { Aperfeiçoamento da "sua } \\
\text { educação e prática } \\
\text { profissional". }\end{array}$ & $\begin{array}{c}\text { Bordéus, } \\
\text { Toulouse e } \\
\text { Montpellier }\end{array}$ \\
\hline $\begin{array}{l}\text { Agostinho Jorge } \\
\text { da Silva* }\end{array}$ & Liceu de Coimbra & $2 .^{\circ}$ & $\begin{array}{l}\text { Aperfeiçoar os } \\
\text { conhecimentos de } \\
\text { francês. }\end{array}$ & França \\
\hline
\end{tabular}




\begin{tabular}{|c|c|c|c|c|}
\hline $\begin{array}{l}\text { Basílio Ribeiro } \\
\text { Leite de Sousa } \\
\text { Vasconcelos* }\end{array}$ & $\begin{array}{l}\text { Liceu de Alexandre } \\
\text { Herculano }\end{array}$ & $2 .^{\circ}$ & $\begin{array}{l}\text { Aperfeiçoar } \\
\text { conhecimentos } \\
\text { francês e de metodologia } \\
\text { das línquas vivas. }\end{array}$ & $\begin{array}{l}\text { Bordéus, } \\
\text { Toulouse, } \\
\text { Montpellier, } \\
\text { Paris : Suíca }\end{array}$ \\
\hline $\begin{array}{l}\text { Gastão Correia } \\
\text { Mendes* }\end{array}$ & \begin{tabular}{|lll} 
Liceu de & Gil \\
Vicente & &
\end{tabular} & $2 .^{\circ}$ & $\begin{array}{l}\text { Estudar a metodologia } \\
\text { das línguas vivas e a } \\
\text { organização das escolas } \\
\text { de ensino médio. }\end{array}$ & $\begin{array}{l}\text { Montpellier; } \\
\text { Suíça }\end{array}$ \\
\hline $\begin{array}{l}\text { José António } \\
\text { Dentinho Júnior }\end{array}$ & Liceu de Faro & $2 .^{\circ}$ & $\begin{array}{l}\text { Estudar o "modo como é } \\
\text { aplicado o método direto } \\
\text { no ensino das línguas } \\
\text { vivas nos liceus." }\end{array}$ & $\begin{array}{c}\text { Zurique } \\
\text { (estabeleciment } \\
\text { os de ensino } \\
\text { secundário) }\end{array}$ \\
\hline $\begin{array}{l}\text { Luís da Câmara } \\
\text { Reis }\end{array}$ & $\begin{array}{lll}\text { Liceu de } & \text { Gil } \\
\text { Vicente } & & \end{array}$ & $2 .^{\circ}$ & $?$ & $\begin{array}{l}\text { Suíça e Itália } \\
\text { ou sul de } \\
\text { França }\end{array}$ \\
\hline $\begin{array}{l}\text { João Gualberto } \\
\text { de Barros e } \\
\text { Cunha* }\end{array}$ & Liceu de Coimbra & $3 .^{\circ}$ & $\begin{array}{l}\text { Renovar } \text { os } \\
\text { conhecimentos práticos } \\
\text { da língua inglesa... } \\
\text { "conhecer os processos } \\
\text { atualmente mais usados } \\
\text { para o ensino da língua } \\
\text { inglesa nos liceus } \\
\text { franceses". }\end{array}$ & $\begin{array}{l}\text { Londres, } \\
\text { Oxford ou } \\
\text { Cambridge; } \\
\text { França }\end{array}$ \\
\hline $\begin{array}{l}\text { Damião António } \\
\text { Peres* }\end{array}$ & \begin{tabular}{|lll} 
Liceu & de & Gil \\
Vicente & & \\
\end{tabular} & $4 .^{\circ}$ & $\begin{array}{l}\text { "Visitar as instalações } \\
\text { dos gabinetes de } \\
\text { geografia" e estudar a } \\
\text { forma como é ministrado } \\
\text { o ensino dessa } \\
\text { disciplina. }\end{array}$ & $\begin{array}{l}\text { Espanha } \\
\text { (principais } \\
\text { cidades } \\
\text { universitárias) }\end{array}$ \\
\hline $\begin{array}{ll}\text { Fidelino de } & \text { de } \\
\text { Sousa } & \\
\text { Figueiredo* } & \end{array}$ & Liceu de Maria Pia & $5 .^{\circ}$ & $\begin{array}{l}\text { Estudar a organização } \\
\text { dos estudos secundários } \\
\text { e superiores de ciências } \\
\text { históricas e dos serviços } \\
\text { de bibliotecas. }\end{array}$ & $\begin{array}{l}\text { Espanha } \\
\text { (Madrid, } \\
\text { Salamanca, } \\
\text { Barcelona) }\end{array}$ \\
\hline $\begin{array}{l}\text { José Ribeiro } \\
\text { Baptista } \\
\text { Caldeira* }\end{array}$ & $\begin{array}{l}\text { Liceu de Rodrigues } \\
\text { de Freitas }\end{array}$ & $6^{\circ}$ & $\begin{array}{l}\text { Observar os métodos e } \\
\text { processos de ensino } \\
\text { secundário. }\end{array}$ & $\begin{array}{c}\text { Espanha, } \\
\text { França e Suíça }\end{array}$ \\
\hline $\begin{array}{l}\text { Álvaro } \\
\text { Rodrigues } \\
\text { Machado* }\end{array}$ & $\begin{array}{l}\text { Liceu de Rodrigues } \\
\text { de Freitas }\end{array}$ & $7 .^{\circ}$ & $\begin{array}{l}\text { "Estudo do conjunto e } \\
\text { comparativo do ensino } \\
\text { da física, tirando daí as } \\
\text { aprofundações às } \\
\text { escolas portuguesas". }\end{array}$ & $\begin{array}{l}\text { Inglaterra e } \\
\text { outros países } \\
\text { (escolas } \\
\text { secundárias e } \\
\text { superiores) } \\
\end{array}$ \\
\hline $\begin{array}{l}\text { José Duarte } \\
\text { Carrilho* }\end{array}$ & Liceu de Braga & $7 .^{\circ}$ & $?$ & $\begin{array}{c}\text { Espanha, } \\
\text { França e Itália }\end{array}$ \\
\hline $\begin{array}{ll}\text { Luís Maria } & \text { de } \\
\text { Passos } & \text { da } \\
\text { Silva* } & \end{array}$ & \begin{tabular}{|lll} 
Liceu de & Gil \\
Vicente & &
\end{tabular} & $9 .^{\circ}$ & $?$ & $?$ \\
\hline
\end{tabular}


Documentação de arquivo deixa, na verdade, perceber que a escolha dos candidatos teve em conta o mérito próprio. Entre os bolseiros ou pensionistas contam-se, por exemplo, personalidades como Damião Peres $^{6}$ e Fidelino de Figueiredo. ${ }^{7}$ Por outro lado é interessante notar que alguns dos candidatos foram preferidos pela circunstância de serem, cumulativamente, professores de metodologia das Escolas Normais Superiores. Os docentes em causa estavam "naturalmente indicados para a viagem, visto que aperfeiçoados eles, aperfeiçoado ficará o ensino feito depois e consequentemente mais habilitados os alunos-mestres" (Ahmec, Ministério da Instrução Pública, documentação em fase de tratamento arquivístico).

É curioso, e por demais significativo, o teor da documentação produzida no âmbito das missões de estudo ao estrangeiro - processos de candidatura e relatórios - ${ }^{8}$ designadamente pelo facto de projetar uma determinada visão de futuro. Vejamos, por exemplo, o caso do professor Basílio de Sousa Vasconcelos. ${ }^{9}$ Os objetivos da sua viagem de estudo à França e à Suíça, expressos em 20 de agosto de 1918 na candidatura então submetida, eram, além do aperfeiçoamento na língua francesa, os seguintes:

$\left.1^{\circ}\right)$ Obter esclarecimentos sobre a organização da correspondência interescolar internacional e a suas vantagens;

2. ${ }^{\circ}$ ) Ver se é possível estabelecer-se entre Portugal e França, e mesmo a Suíça, o intercâmbio de alunos e até de professores, pelo menos durante as férias de verão. (Ahmec, Ministério da Instrução Pública, documentação em fase de tratamento arquivístico)

Mas é evidente que a concessão de bolsas era insuficiente para elevar de modo significativo a qualidade pedagógica do professorado do ensino secundário. Sabemos, além do mais, que as Escolas Normais Superiores, desde a data em que foram criadas até ao final da Primeira República, formaram cerca de 160 docentes (Nóvoa, 1989). A renovação do sistema passava obrigatoriamente por uma política sistemática de formação do professorado. Uma questão, recorde-se, para a qual Alice Pestana havia já chamado a atenção, sublinhando a necessidade de uma política de apoio à divulgação de princípios inovadores, designadamente pela criação de escolas-modelo (Pestana, 1915), princípio caro, também, a António Sérgio.

As ideias expostas até ao momento não podem fazer esquecer que, até 1918, não obstante os programas de ação de ministros como Sobral Cid e Alfredo de Magalhães cujos mandatos, convém talvez sublinhá-lo, tiveram alguma continuidade -, as condições operacionais do Ministério da Instrução Pública não se alteraram. A este propósito os relatos são esclarecedores. Fiquemos com um trecho do relatório sobre o estado dos serviços desse organismo da administração, datado de 6 de fevereiro de 1918:

\footnotetext{
${ }^{6}$ Damião Peres foi mais tarde professor das Faculdades de Letras das Universidades do Porto e de Coimbra, tendo sido um insigne historiador e numismata.

${ }^{7}$ Fidelino de Figueiredo viria a destacar-se como professor de literatura portuguesa e espanhola, em diversas universidades: Espanha, Brasil, Estados Unidos da América e México. Foi, ademais, crítico literário.

${ }^{8}$ No Ahmec, fundo citado, localizei apenas o relatório do professor Álvaro Rodrigues Machado. Porém, todos os pensionistas estavam obrigados à elaboração do relatório da viagem de estudo (cf. o Decreto $\mathrm{n}$. 4799, de 8 set. 1918).

${ }^{9}$ Além de professor do Liceu Alexandre Herculano, Basílio de Sousa e Vasconcelos viria a ser, em 1931, o primeiro diretor do Arquivo Distrital do Porto. 
O Ministério funciona nalgumas dependências do Ministério do Interior, sem acomodações para os vários serviços. Em cada repartição as secretárias, os processos e mais papelada atropelam-se confusamente, por falta de espaço e porque mesmo essa exígua instalação é tão extravagante [...] que gera a confusão. O gabinete do secretário-geral é no último andar, mas a secretaria-geral, de que ele é o chefe, funciona no andar nobre, no salão, em algumas pequenas mesas que gravitam em torno da mesa grande do Conselho Superior e Instrução Pública. (apud Silva, 2006, p. 125)

Num outro relatório acerca da atividade do Ministério da Instrução Pública, correspondente ao período de 11 de dezembro de 1917 a 15 de julho de 1918, Alfredo de Magalhães devolve-nos a seguinte imagem:

O Ministério, longe de fomentar, proteger e honrar a cultura do espírito, dela se havia desinteressado, limitando-se à simples administração burocrática, que raramente exerceu com imparcialidade; não era um organismo criado para os professores e homens de estudo, mas uma entidade criada fora deles e contra eles. (apud Silva, 2006, p. 127)

Trata-se, certamente, de uma imagem impressiva, mesmo abstraindo o facto de Alfredo de Magalhães pretender sinalizar uma rutura com o passado anterior à revolução sidonista. O objetivo, esse, era o de legitimar a posteriori um ambicioso projeto de reformas. Deve, porém, enfatizar-se que, salvo raras exceções, a ambição reformista da República se fundou em larga medida na produção legislativa, ignorando as realidades educativas (Nóvoa, 1989).

Como quer que seja, não deixo de assinalar uma das mais significativas medidas legislativas da República, particularmente pela ousadia pedagógica que encerra. Refirome ao ensino primário superior. De facto, consagrado na reforma de 29 de março de 1911, mas só concretizado com a reforma de 1919, ministério de Leonardo Coimbra, a proposta que encerra é a da extensão do ensino primário a oito anos abrangendo, dessa forma, crianças até aos 15 anos de idade. Acresce a tentativa de aliar uma formação geral a uma preparação de caráter técnico adequada às necessidades concelhias. Não se estranha, assim, que as comunidades locais encarem as escolas primárias superiores como instituições de ensino populares e democráticas, cujo sentido, no seu entender, só poderia ser o da ligação às economias prioritárias.

É certo que o ensino primário superior teve uma existência atribulada, vivendo, de resto, um conjunto de contradições - entre ser escola ou oficina, entre ser o fim do primário ou o início do secundário -, mas está por conhecer o alcance social da ação das cerca de 50 escolas que funcionaram entre 1919 e $1926 .{ }^{10}$ Em que medida, por exemplo, foram capazes de aproximar a formação escolar e profissional?

Em 1924, a extinção das escolas primárias superiores, a instâncias do ministro António Sérgio, provocou uma série de reações, não apenas da parte do professorado desse grau de ensino, entretanto, constituído em associações profissionais.

\footnotetext{
${ }^{10}$ Para esse conhecimento seria importante a realização de estudos monográficos, na linha, por exemplo, do trabalho de Silva (2012). 
Talvez seja interessante explorar o argumentativo de António Sérgio no que concerne à sua decisão enquanto ministro da Instrução. Para o efeito, mobilizo uma entrevista que o autor dos Ensaios concedeu a um periódico da capital, em 16 de junho de 1926, justamente no dia seguinte ao da publicação do decreto que extinguiu definitivamente o ensino primário superior ${ }^{11}$. Sérgio sustenta então que a sua ideia não fora, verdadeiramente, a de abolir o ensino primário superior, bem pelo contrário: suprimira as escolas "para poder reformar de raiz o ensino primário superior português" (IAN/TT, Ministério do Interior, DGAPC, NT-696, pt. 704). Esse esforço reformista, segundo expressava, significaria obrigatoriamente uma aproximação "ao ensino de continuação" alemão. De facto, como medidas, Sérgio propunha: a criação de duas escolas primárias superiores a "valer"; a contratação, para lecionar as seções técnicas, de pessoal estrangeiro, "preferentemente professores alemães das escolas fundadas e dirigidas na Baviera por Kerschensteiner" (IAN/TT, Ministério do Interior, DGAPC, NT-696, pt. 704).

Depois de fundadas essas escolas-modelo, então far-se-iam outras à sua imagem, tentando-se "desviar para elas uma grande parte da juventude que vai para os liceus e não tem dotes intelectuais" (IAN/TT, Ministério do Interior, DGAPC, NT-696, pt. 704). Estas ideias estavam, de resto, em linha com o que Sérgio defendera no relatório de saída do Ministério, em 1924, lembrando ao seu sucessor: a importância da formação do professorado, bem como da existência de escolas modelares ou experimentais, a partir das quais surgiria para outras o exemplo. O impulso reformador, lê-se igualmente no dito relatório, passava também pelo envio de professores e de estudiosos a escolas estrangeiras de referência. Conforme sublinhou Rogério Fernandes, o pressuposto era o de lançar "um microssistema paralelo, cujos efeitos se poderiam apenas manifestar a longo prazo" (Fernandes, 1983, p. 641).

Para além das citadas intenções, António Sérgio, na sua fugaz passagem pelo Ministério, tomou outras iniciativas de renovação pedagógica, não se tratando, porém, pela escassez de meios, de ações diretas de apoio ao professorado. Refira-se, a título de exemplo, a criação do Boletim Pedagógico, destinado a difundir, entre o professorado, os novos processos de ensino. O primeiro número publicado e, sintomaticamente, último, dedicava especial atenção à metodologia do ensino da leitura, mobilizando as contribuições didáticas de Montessori e de Decroly. Decerto uma inovação metodológica que, para produzir resultados, pressuporia um apoio direto aos professores.

É tempo de concluir. Recorro a um autor como Sérgio Grácio (1993) e ao seu pressuposto de ser difícil de aceitar, no contexto de instabilidade política que caraterizou a Primeira República, a ideia de se ter "constituído algo de coerente no domínio da política de ensino" (p. 78). De facto, citando, uma vez mais, Sérgio Grácio, “as medidas dirigentes [...] só ganham um sentido mais completo uma vez posicionadas no conjunto das medidas adotadas e da evolução de todo o sistema de ensino" (p. 78). Era esse, de resto, o sentido da proposta de lei da Reforma da Educação do ministro João Camoesas (1923), demais objeto de profundo debate no mundo pedagógico. ${ }^{12}$ Da longa nota preambular não ficou excluído o diagnóstico à administração do ensino, sublinhando-se: a dispersão dos

\footnotetext{
${ }^{11}$ Não consegui identificar o título do periódico. Consultei o citado artigo por uma fonte indireta (IAN/TT, Ministério do Interior, DGAPC, NT-696, pt. 704).

12 Importa dizer que o diploma foi apresentado ao Parlamento em 1923, sendo que nunca chegou a ser discutido. 
serviços por vários ministérios, o que trazia "um desperdício de forças, de dinheiro, de homens, de eficiência"; a "permanente confusão das atividades técnicas e administrativas e a sua centralização burocrática nos mesmos órgãos"; a "falta de um órgão de coordenação superior que estabeleça entre as diferentes funções as ligações necessárias"; a "falta de órgãos vivos e plásticos, representativos dos diferentes interesses do ensino, que funcionem como corpos consultivos técnicos e adequados" (Diário do Governo, n. 151, 2 jul. 1923, p. 2262).

Se é verdade que a obra educativa da Primeira República não foi, em muitos casos, além das intenções legislativas - o balanço, todavia, ainda não está totalmente realizado -, não menos certo é dizer que deixou realizações de inegável mérito, construídas, sobretudo, à margem do sistema de ensino oficial (Nóvoa, 1989). Nesse período histórico, tendo em conta as circunstâncias assinaladas, de natureza política, sobretudo, a existência de um órgão central de coordenação do sistema educativo, impelido e legitimado pela referência ao estrangeiro e a modelos reformadores da educação, não se traduziu em maior capacidade para desenvolver de forma coerente e decisiva, portanto, por dinâmicas inovadoras.

\section{Referências}

DINIZ, Aires; BONITO, Jorge. O berço do ensino experimental em Sobral Cid. CONGRESSO LUSO-BRASILEIRO DE HISTÓRIA DA EDUCAÇÃO, 8, 2010. Anais ... São Luís: SBHE, 2010.

CID, José Maria Sobral. Obras. Lisboa: Fundação Calouste Gulbenkian, 1983.

FERNANDES, Rogério. João de Barros educador republicano. Porto: Livros Horizonte, 1971.

FERNANDES, Rogério. António Sérgio Ministro da Instrução Pública. Revista de História das Ideias, Coimbra, v. 5, tomo 2, 1983, p. 603-700.

FERNANDES, Rogério. Ensaios de modernização do ensino liceal e investigação pedagógica no limiar do século XX. Ciências da Educação: investigação e ação. Porto: Sociedade Portuguesa de Ciências da Educação, v. 1, 1995, p. 331-340.

FERNANDES, Rogério. Irene Lisboa e Áurea Judite Amaral: dois olhares sobre a escola a partir da "Escola Nova". In: GONDRA, José; MIGNOT, Ana Chrystina (orgs.). Viagens pedagógicas. São Paulo: Cortez, 2007, p. 217-245.

GRÁCIO, Sérgio. Uma interpretação da política de ensino na I República. Fórum Sociológico, Lisboa, n. 2, 1993, p. 77-91.

HAMELINE, Daniel; NÓVOA, António. Autobiografia inédita de António Sérgio: escrita aos 32 anos no Livro D'Or do Instituto Jean-Jacques Rousseau (Genéve). Revista Crítica e Ciências Sociais, Coimbra, n. 29, 1990, p. 141-177.

GONDRA, José; MIGNOT, Ana Chrystina (orgs.). Viagens pedagógicas. São Paulo: Cortez, 2007.

$\mathrm{KIM}$, Jong-Seon. The normative construction of modern state systems: educational ministries and laws, 1800-2000. In: BAKER, David P; WISEMAN, Alexander W (editors.). The impact of comparative education research on institutional theory. Oxford: Jay Press Publications, 2006, p. 137-156.

NÓVOA, António. A república e a escola: das intenções generosas ao desengano das realidades. Lisboa: IIE, 1989, v. 1, tomo II, p. IX-XXIV. 
PESTANA, Alice. La educación en Portugal. Madrid: Junta para Amp. de Est. e Inv. Científicas, 1915.

PINTASSILGO, Joaquim. Imagens e leituras da educação nova em Portugal: os relatórios de bolseiros portugueses em visita a instituições educativas europeias (1907-1909). In: GONDRA, José; MIGNOT, Ana Chrystina (orgs.). Viagens pedagógicas. São Paulo: Cortez, 2007, p. 195-216.

SILVA, Armando Malheiro da. Sidónio e sidonismo: história de um caso político. Coimbra: Imprensa da Universidade, 2006.

SILVA, Carlos Manique da. O ensino primário superior em Sintra (1919-1926). In: ADÃO, Áurea, PINTASSILGO, Joaquim; SILVA, Carlos Manique da (orgs.). O homem vale, sobretudo, pela educação que possui: revisitando a primeira reforma republicana do ensino infantil, primário e normal. Lisboa: Instituto de Educação da Universidade de Lisboa, 2012, p. 63-80.

SILVA, Carlos Manique da. Notícia sumária sobre as instituições escolares da Suíça (1911). Hist. Educ. (Online), Porto Alegre, Asphe, v. 17, n. 41, 2013, p. 235-249.

SOTTOMAYOR CARDIA, Mário. Seara nova: antologia. Lisboa: Seara Nova, 1971.

CARLOS MANIQUE DA SILVA é investigador da Unidade de Investigação e Desenvolvimento em Educação e Formação, Instituto de Educação da Universidade de Lisboa. Tem doutorado em Ciências da Educação, especialidade História da Educação, e como áreas de interesse a circulação e difusão do conhecimento pedagógico, a escola graduada, o ensino mútuo e a arquitetura escolar.

Endereço: Rua Casal do Carantão, 10 - 2655-430 - Ericeira - Portugal.

E-mail: manique@net.sapo.pt.

Recebido em 20 de março de 2016.

Aceito em 11 de julho de 2016. 